\title{
Study of epitaxial films of Ag, Pd and AgPd deposited by dc sputtering
}

\author{
François Reniers, Paule Kons, Pierre Delcambe, Lucien Binst, Marcelle Jardinier-Offergeld \\ and Florent Bouillon
}

Laboratoire de Chimie Analytique, Faculté des Sciences, C. P. 160, Université Libre de Bruxelles, 50 avenue F. D. Roosevelt, 1050 Bruxelles, Belgium

(Received June 18, 1990 ; accepted September 05, 1990)

\begin{abstract}
Résumé. - Nous décrivons les conditions de préparation de films minces épitaxiques d'argent, de palladium et d'alliages argent-palladium déposés sur des faces (100) de $\mathrm{MgO}$ par pulvérisation cathodique. L'orientation parallèle $(100)_{\mathrm{d}} / /(100)_{\mathrm{s}}$ (d pour dépôt et $\mathrm{s}$ pour substrat) est observée pour les deux derniers systèmes. Les films sont caractérisés par THEED, RHEED, SAD, TEM et AES. La composition massive des alliages est déterminée par ICP. La pureté superficielle des films condensés est étudiée et discutée.
\end{abstract}

\begin{abstract}
The experimental conditions to condense epitaxial films of silver, palladium and silverpalladium alloys onto (100) air-cleaved $\mathrm{MgO}$ faces by glow discharge sputtering are related. The orientation $(100)_{d} / /(100)_{s}$ (where $d$ indicates deposit and $s$ substrate) is observed for the two last systems. The films are characterized by THEED, RHEED, SAD, TEM and AES. The bulk composition of the alloys is determined by ICP. The surface purity of the condensed films is examined and discussed.
\end{abstract}

\section{Introduction.}

Silver-palladium coatings have many industrial applications such as electrical contacts, dental alloys, catalysis,... As the properties of thin films depend strongly on their structure, composition and purity, we propose to condense silver-palladium alloy films onto single-crystal substrates by glow discharge sputtering.

In a previous paper [1] we have shown that epitaxial films of $\mathrm{Ag}, \mathrm{Pd}$ and $\mathrm{AgPd}$ alloys deposited onto $\mathrm{NaCl}$ were chloride contaminated. In order to overcome this, we tried to prepare single crystal films of $\mathrm{Ag}, \mathrm{Pd}$ and $\mathrm{AgPd}$ on $\mathrm{MgO}$ single crystals. The deposition of such films by thermal evaporation was the subject of several investigations [2,4]. Asskali [5] obtained good epitaxial (100) palladium films onto $\mathrm{MgO}$ by glow discharge sputtering. We showed [1] that by simultaneous sputtering of both elements, it was possible to obtain monophase alloys at various concentrations. In the present work, we examined the purity of epitaxial alloy films deposited onto $\mathrm{MgO}$ (100). 


\section{Experimental technique.}

The substrates were air cleaved (100) faces of $\mathrm{MgO}$ single crystals (purity 99.9\%). After chemical polishing in a $\mathrm{HCl}(4 \mathrm{M})-\mathrm{CH}_{3} \mathrm{OH}$ solution and annealing two hours at $973 \mathrm{~K}$ in vacuum [6] they showed reflexion high energy electron diffraction (RHEED) patterns characteristic of (100) single crystal faces (Fig. 1). Auger electron spectroscopy was used for purity testing of the films. Auger measurements were performed on a V.G. LEED-Auger spectrometer with a retarding field analyser using a $2.5 \mathrm{keV}$ electron gun incident at $77^{\circ}$ with respect to the sample normal. This grazing incidence is known to increase the surface sensitivity of Auger electron spectroscopy.

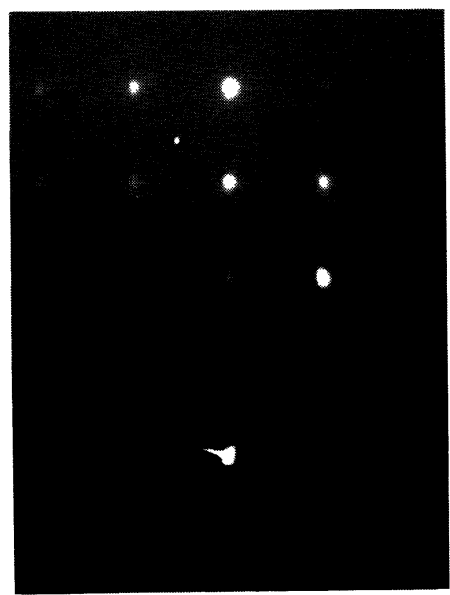

a)

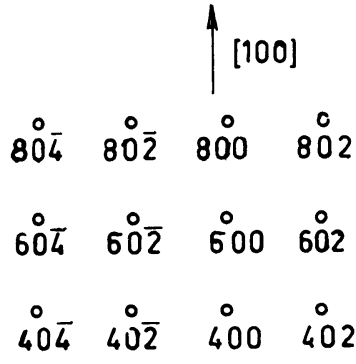

$\overrightarrow{[001]}$

b)

Fig. 1. - a) RHEED pattern of a $\mathrm{MgO}$ (100) face after chemical polishing and annealing.

b) Pattern interpretation: orientation (100) azimuth $<010\rangle$.

After chemical $\left(\mathrm{HCl}(6 \mathrm{M}) \mathrm{CH}_{3} \mathrm{OH}\right)$ stripping from the $\mathrm{MgO}$ substrate, the films were studied by transmission electron microscopy (TEM), selected area diffraction (SAD) and transmission high energy electron diffraction (THEED). The films compositions were determined using inductively coupled plasma atomic emission spectroscopy (ICP).

2.1 Glow Discharge SPUTtERING. - Films were deposited in a d.c. glow discharge in pure argon (99.995\%) between two planar electrodes. The residual pressure before argon admission was never greated than $6 \times 10^{-5} \mathrm{~Pa}$. The cathode was either a disc of pure silver $(99.99 \%)$, a high pressure compacted disc of palladium powder $(99.9 \%)$ or a disc of pure silver partially covered with palladium. A drawing of the experimental system was presented in part I [1]. The MgO substrate was $40 \mathrm{~mm}$ away from the cathode and was in close contact with a copper block heated by an inserted Xenophot $100 \mathrm{~W}, 12 \mathrm{~V}$ lamp. The substrate temperature was measured by a $\mathrm{Ni} / \mathrm{NiCr}$ thermocouple located in the heated copper block. We do not obtain the real surface temperature by this method but it gives a good reproducibility. The pumping system consisted of a turbomolecular pump in order to minimize carbon contamination. 
2.2 INDUCTIVELY COUPLED PLASMAATOMICEMISSIONSPECTROSCOPY (ICP). - The alloy films were dissolved in $\mathrm{HNO}_{3} 65 \%$ p.a. (Merck) then diluted to obtain $5 \mathrm{ml}$ of a $5 \%$ acid solution. Two standard solutions containing $10 \mathrm{ppm}$ of $\mathrm{Ag}$ and $\mathrm{Pd}$ were prepared by dissolution of $\mathrm{AgNO}_{3}$ and $\mathrm{Pd}\left(\mathrm{NO}_{3}\right)_{2} \cdot 2 \mathrm{H}_{2} \mathrm{O}$ in a $5 \% \mathrm{HNO}_{3}$ solution. The measurements were performed on an ICP spectrometer IL-100 from Instrumentation Laboratory.

\section{Experimental results.}

The epitaxial conditions for various systems are summarized in table I and electron diffraction patterns are shown in figures 2-5. Although the lattice misfit is small between $\mathrm{Ag}$ and $\mathrm{MgO}$ (see Tab. II), no good epitaxy was observed for this system. This result agrees partly with the literature : Green et al. [7] could not obtain epitaxial silver films onto air-cleaved $\mathrm{MgO}$ faces by thermal evaporation and Kahn et al. [8] condensed polycrystalline silver films on $\mathrm{MgO}$ by sputtering. However, a beginning of orientation is observed (Fig. 2). As it is possible to prepare epitaxial silver films onto vacuum-cleaved $\mathrm{MgO}$ [7], the surface state of the substrate probably plays a critical role in the epitaxy of silver.

Table I. - Epitaxial conditions by glow discharge sputtering.

\begin{tabular}{lccccccc}
\hline $\begin{array}{l}\text { Cathode } \\
\text { composition }\end{array}$ & $T(\mathrm{~K})$ & $V(\mathrm{kV})$ & $p(\mathrm{~Pa})$ & $I(\mathrm{~mA})$ & $t(\mathrm{~nm})$ & annealing & remarks \\
\hline $\mathrm{Ag}$ & 748 & 3.0 & 6.7 & 6 & 62 & - & $\mathrm{a}$ \\
$\mathrm{Ag}_{70} \mathrm{Pd}_{30}$ & 888 & 4.0 & 4.0 & 6 & 80 & - & \\
$\mathrm{Ag}_{50} \mathrm{Pd}_{50}$ & 913 & 3.0 & 10.6 & 6 & 75 & $2 \mathrm{~h}$ at $863 \mathrm{~K}$ & $\mathrm{c}$ \\
$\mathrm{Ag}_{30} \mathrm{Pd}_{70}$ & 973 & 3.0 & 10.1 & $5-6$ & 64 & 1 h at $893 \mathrm{~K}$ & $\mathrm{~d}$ \\
$\mathrm{Ag}_{13} \mathrm{Pd}_{87}$ & 1023 & 3.0 & 10.0 & $5-6$ & 76 & 1 h at $893 \mathrm{~K}$ & \\
$\mathrm{Pd}$ & 1053 & $2-2.6$ & 8.0 & 6 & 72 & - & b \\
\hline
\end{tabular}

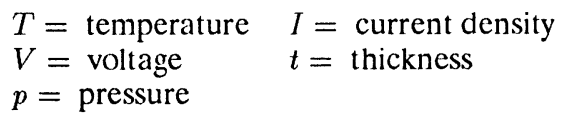

\section{Remarks :}

a) no epitaxy of silver is observed. However a beginning of orientation is shown in figure 2

b) perfect parallel epitaxy of palladium was obtained. The Kikuchi lines in figure 3 show the perfection of the crystal lattice

c) a diffraction pattern is presented figure 4

d) a diffraction pattern is presented figure 5 


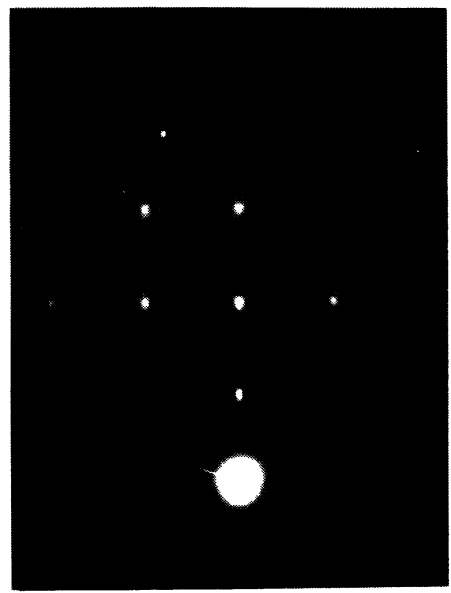

a)

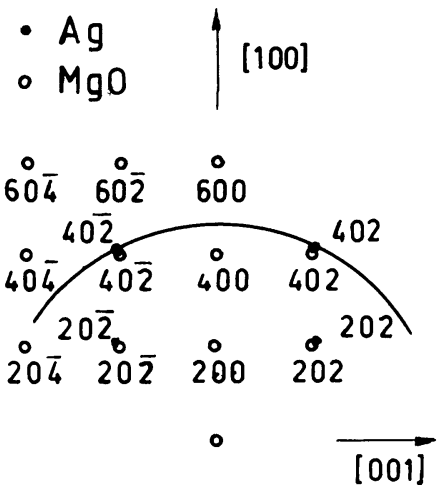

b)

Fig. 2. - a) RHEED pattern of a $\mathrm{Ag}$ film deposited on $\mathrm{MgO}$ under the conditions listed in table I.

b) Pattern interpretation.

Table II.

\begin{tabular}{lcc}
\hline system & $\begin{array}{l}\text { lattice misfit for } \\
(100)_{\mathrm{d}}<011>_{\mathrm{d}} / /(100)_{\mathrm{s}}<011>_{\mathrm{s}}\end{array}$ & $\begin{array}{c}\text { lattice misfit for } \\
(100)_{\mathrm{d}}<011>_{\mathrm{d}} / /(100)_{\mathrm{s}}<001>_{\mathrm{s}}\end{array}$ \\
\hline $\mathrm{Ag} / \mathrm{NaCl}$ & $-27.5 \%$ & $-48.8 \%$ \\
$\mathrm{Pd} / \mathrm{NaCl}$ & $-31.0 \%$ & $-51.2 \%$ \\
$\mathrm{Ag} / \mathrm{MgO}$ & $-3.0 \%$ & $-31.4 \%$ \\
$\mathrm{Pd} / \mathrm{MgO}$ & $-7.7 \%$ & $-34.7 \%$ \\
$\mathrm{Ag} / \mathrm{Pd}$ & $-5.0 \%$ & $-25.7 \%$ \\
\hline
\end{tabular}

We obtained a perfect parallel orientation of Pd (Fig. 3) and AgPd alloys (Figs. 4, 5) on $\mathrm{MgO}$ (100). The epitaxial temperature is higher on $\mathrm{MgO}$ than on $\mathrm{NaCl}$ (see Tab. III). Tables I and III suggest also that the epitaxial temperature of the alloys increases with the Pd concentration.

We studied the spectral lines of silver at $328.068 \mathrm{~nm}$ and palladium at $340.458 \mathrm{~nm}$ by ICPatomic emission spectrometry. The spectrometer was calibrated with the first standard solution and a blank solution containing $5 \% \mathrm{HNO}_{3}$. The reliability of the method was checked with the two standard solutions. The deviation was never larger than $2 \%$. Table IV shows the relation between the target composition and the film composition. The silver concentration is always higher in the film than on the target. This is probably due to the relative sputtering yield of silver and palladium. Seah [9] gives a ratio $Y_{\mathrm{Ag}} / Y_{\mathrm{Pd}}$ of 1.4 and Mathieu and Landolt [10] a ratio of 1.89.

AES was used to estimate the purity of our films. We showed [1] that films deposited onto heated rocksalt (100) faces were heavily chloride contaminated even in the bulk. Figure 6 shows an AES spectrum of a silver-palladium alloy film deposited onto $\mathrm{MgO}$ (100) at $973 \mathrm{~K}$. 


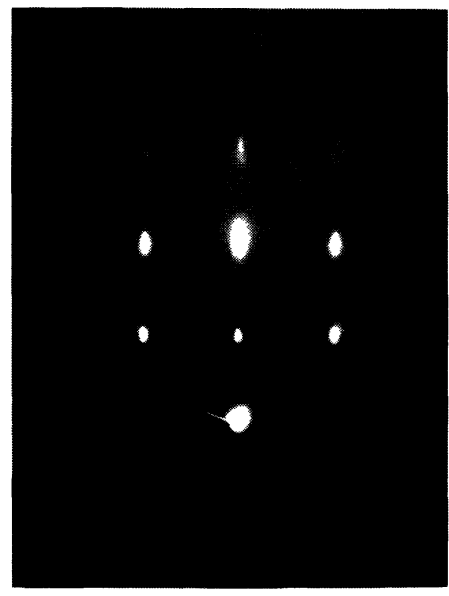

a)

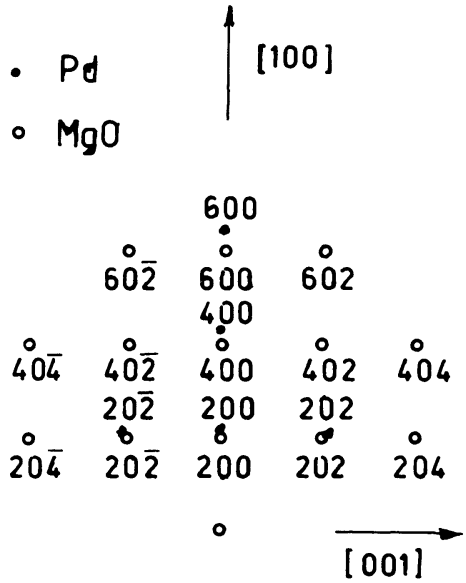

b)

Fig. 3. - a) RIIEED pattern of a Pd film deposited on $\mathrm{MgO}$ under the conditions listed in table I.

b) Pattern interpretation: orientation : $(100)<011>/ /(100)<011>$

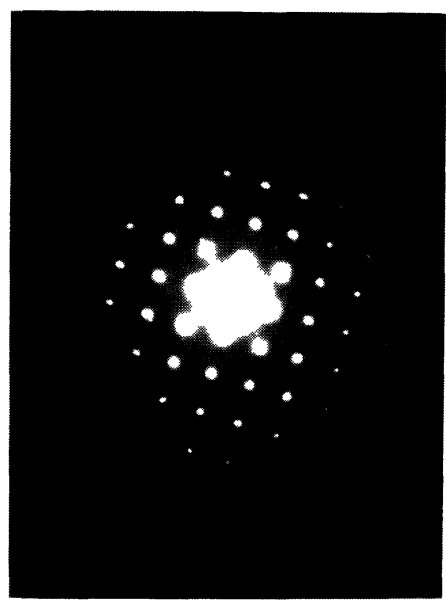

a)

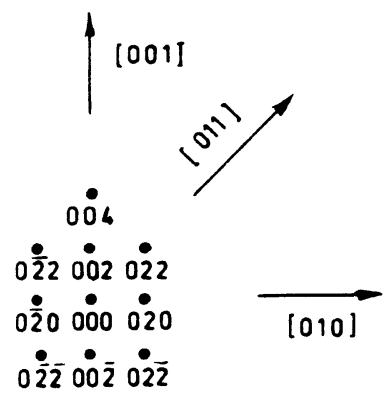

b)

Fig. 4. - a) SAD pattern of a AgPd film deposited on $\mathrm{MgO}$ under the conditions listed in table I. b) Pattern interpretation.

The surface of the sample has been cleaned by ion bombardment $\left(\mathrm{Ar}^{+}\right.$, energy $=4 \mathrm{keV}$, pressure $=$ $\left.1.33 \times 10^{-4} \mathrm{~Pa}\right)$ and annealed $(>773 \mathrm{~K})$. Therefore, no significant contamination of the restored sample is observed by Auger electron spectroscopy. It must be stressed that the carbon $272 \mathrm{eV}$ peak is overlapped by the $\mathrm{Pd} 279 \mathrm{eV}$ peak, so it is difficult to assert that no carbon is present. We obtain a ratio $\mathrm{Pd}(279 \mathrm{eV}) / \mathrm{Pd}(330 \mathrm{eV})=0.16$. This value is given by Vankar and Vook [11] for a palladium surface free of carbon. Even when the sample was heated for 5 hours at $843 \mathrm{~K}$, the ratio didn't increase. The C $272 \mathrm{eV}$ peak may also overlap with the Ag 261-266 eV. In order to 


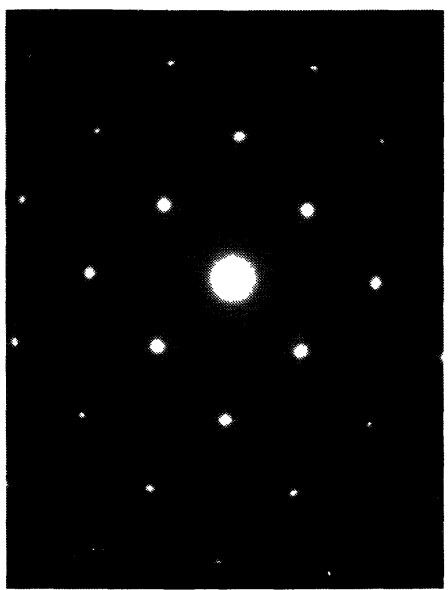

a)

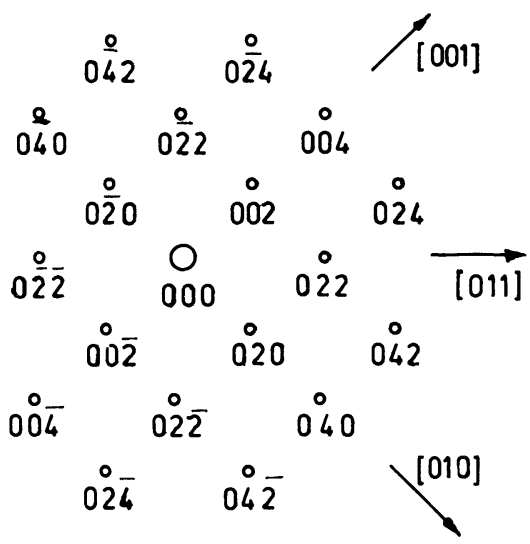

b)

Fig. 5. - a) THEED pattern of a AgPd film deposited on $\mathrm{MgO}$ under the conditions listed in table I. b) Pattern interpretation.

Table III. - A comparison between epitaxial temperatures (K) on $\mathrm{NaCl}(100)$ and $\mathrm{MgO}(100)$.

\begin{tabular}{lcccc}
\hline Target composition & $\mathrm{Ag}$ & $\mathrm{Pd}$ & $\mathrm{Ag}_{70} \mathrm{Pd}_{30}$ & $\mathrm{Ag}_{50} \mathrm{Pd}_{50}$ \\
\hline $\mathrm{NaCl}[1]$ & 383 & 898 & 783 & 863 \\
$\mathrm{MgO}$ & $(748)$ & 1053 & 888 & 913 \\
\hline
\end{tabular}

Table IV. - Comparison between the target composition and the film composition.

\begin{tabular}{cccc}
\hline $\begin{array}{c}\text { target composition } \\
\text { \% Pd }\end{array}$ & Ag & \multicolumn{2}{c}{ film composition } \\
\% Pd & \% Ag \\
\hline 87 & 13 & 72 & 28 \\
70 & 30 & 52 & 48 \\
50 & 50 & 40 & 60 \\
30 & 70 & 14 & 86 \\
\hline
\end{tabular}

establish the absence of carbon, most investigators rely on the ratio $R=\left(\mathrm{C}_{272}+\mathrm{Ag}_{261-266}\right) /$ $\mathrm{Ag}_{303 \mathrm{eV}}$ [12]. $R$ values for clean silver are in the range of $0.42-0.55$ depending on the modulation voltage. We found a ratio of 0.5 . No oxygen was detected after ion cleaning and sample 


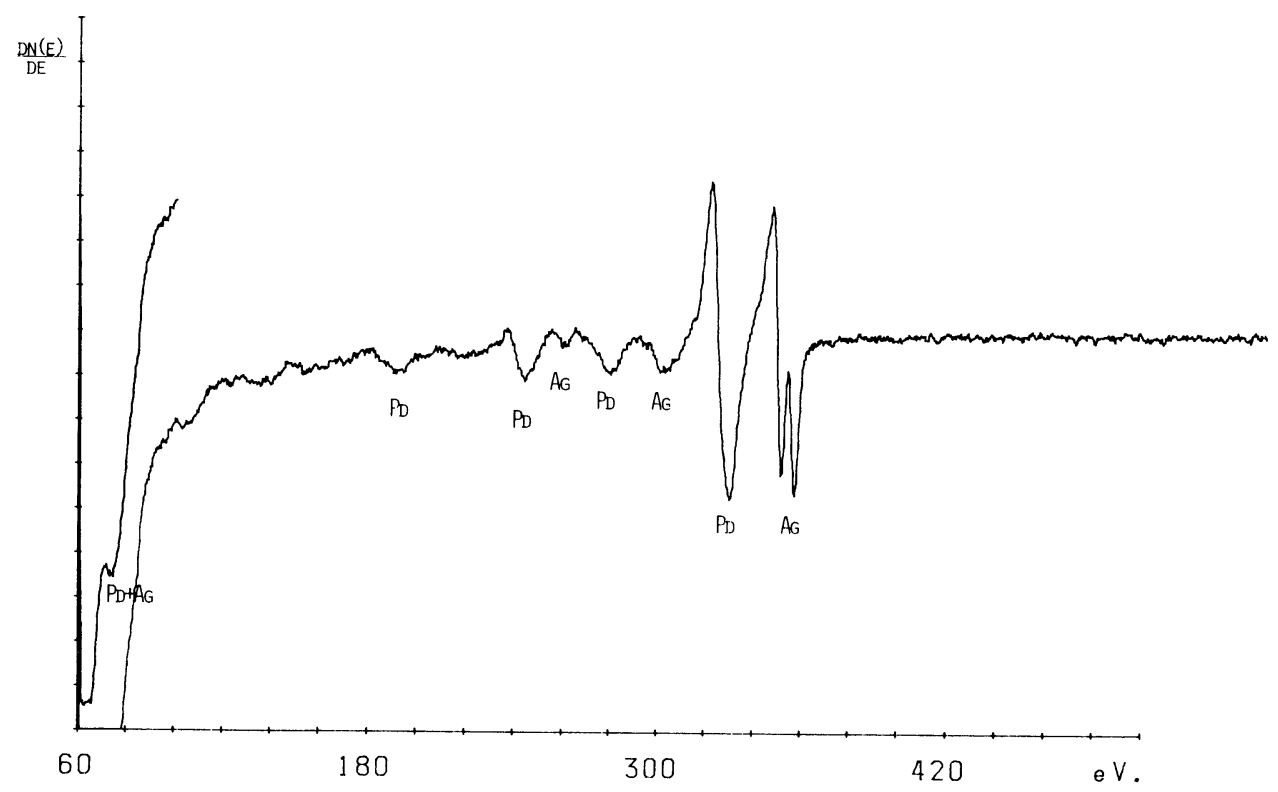

Fig. 6. - AES spectrum of an AgPd alloy deposited onto $\mathrm{MgO}$ after ion cleaning; modulation voltage $=2.75 \mathrm{~V}, \mathrm{E}_{\mathrm{p}}=2.5 \mathrm{keV}$.

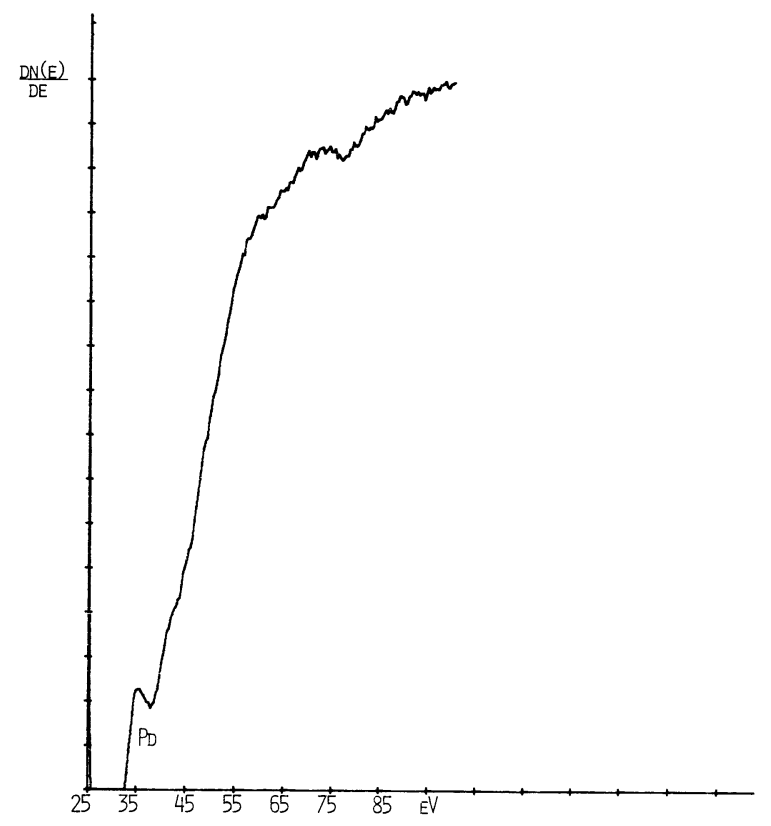

Fig. 7. - AES spectrum of an AgPd alloy deposited onto $\mathrm{MgO}$ after ion cleaning; modulation voltage $=1.75 \mathrm{~V}, E_{\mathrm{p}}=2.5 \mathrm{keV}$. 
heating. This justifies the choice of magnesium oxyde as a high stability substrate. No sulfur is present on the sample after bombardment but a small sulfur segregation is observed when heating. The sulfur contamination remains however weak ( $<$ than $6 \%$ on the surface).

The surface cleanliness of a sample can also be qualitatively studied by observing the low energy region of the Auger spectrum. As it is known that low energy Auger peaks are typical of the very first atomic layers, the presence of the $\mathrm{Pd}$ peak at $39 \mathrm{eV}$ in figure 7 proves the cleanliness of the surface. Indeed, according to the Pons et al. model [13] and using the Seah and Dench formula for the attenuation length [14], more than $80 \%$ of the signal of the Pd $\mathrm{N}_{2,3} \mathrm{~N}_{4,5} \mathrm{~N}_{4,5}$ transition comes from the two first atomic layers. The energy shift relative to the literature (44 eV) is probably due to charging effects of the substrate. A palladium foil half-covered with silver was used to determine a relative Auger yield (S). With a primary beam energy of $2.5 \mathrm{keV}$ and a modulation voltage of $2.7 \mathrm{~V}, \mathrm{~S} \mathrm{Ag}(351-356 \mathrm{eV}) / \mathrm{Pd}(330 \mathrm{eV})=1.14$. This value corresponds to the value given by Mathieu [15]. After several ion-sputtering and heating cycles, the silver and palladium atomic concentrations remain constant for all the films studied. This demonstrates the good bulk homogeneity of our films.

\section{Conclusions.}

Preparation of epitaxial films of palladium and silver-palladium alloys on $\mathrm{MgO}(100)$ faces proved to be easy by glow discharge sputtering. The epitaxial temperature is higher for films deposited on $\mathrm{MgO}$ than for films deposited onto $\mathrm{NaCl}$ and increases with the palladium concentration. Excellent parallel orientations were obtained. The purity of films deposited on $\mathrm{MgO}$ is very good, no significant surface contamination is observed by AES. The bulk composition of the alloy films can easily be determined by ICP.

\section{Acknowledgements.}

The authors are most grateful to the Fonds National de la Recherche Scientifique for financial support. Thanks are also due to OTAN for grant 48.81. We wish to thank M. Hoenig from the laboratory of the Belgian Ministry of Agriculture for ICP measurements. F. Reniers is grateful to the Institut pour l'Encouragement de la Recherche Scientifique dans l'Industrie et l'Agriculture for a specialisation grant.

\section{References}

[1] Reniers F., Binst L., Delcambe P., Jardinier-Offergeld M., Boulllon F., Thin Solid Films 170 (1989) 41-47.

[2] Renou A., Rudra A., Surface Sci. 156 (1985) 69-84.

[3] TaKayanagi K., Yagi K., Honjo G., Thin Solid Films 48 (1978) 137-152.

[4] Heinemann K., Osaka T., Poppa H., Avalos-bor.ja M., J. Catalysis 83 (1983) 61-78.

[5] ASSAKLi A., PhD thesis, Université Libre de Bruxelles (1990).

[6] Delplancke M. P., Delcambe P., Binst L., JaRdinier-Offergeld, Bouillon F., Thin Solid Films 143 (1986) 43-51.

[7] GREen A. K., Dancy J., BAUER E., J. Vacuum Sci. Technol. 7 (1970) 159-163.

[8] Khan M. R., Schuller I. K., FalCo C. M., Phys. Status Solidi (a) 73 (1982) 23-29.

[9] SEAH M. P., Thin Solid Films 81 (1981) 279-287.

[10] Mathieu H. J., LANDOlt D., Surf. Sci. 53 (1975) 228-240. 
[11] VANKaR V. D., VoOK R. W., Surf. Sci. 131 (1983) 473.

[12] Musket R. G., Lean W.Mc, Colmenares C. A., Makowiecki D. M., Siekhaus W. J., Apll. Surf. Sci. 10 (1982) 143-207.

[13] Pons F., LE Hericy J., Langeron J. P., Surf. Sci. 69 (1977) 565.

[14] SEAH M. P., DENCH W. A., Surf. Interf. Anal. 1 (1979) 2.

[15] Mathieu H. J., Landolt D., Appl. Surf. Sci. 10 (1982) 455-465.

Cet article a été imprimé avec le Macro Package "Editions de Physique Avril 1990". 